\title{
Article
}

\section{Race, Ethnicity, Young People and Offending: the Elephant in the Room}

\author{
Wainwright, John Peter and Larkins, Cath \\ Available at http://clok.uclan.ac.uk/30328/ \\ Wainwright, John Peter ORCID: 0000-0002-8190-0144 and Larkins, Cath \\ ORCID: 0000-0003-2999-6916 (2020) Race, Ethnicity, Young People and \\ Offending: the Elephant in the Room. Social Identities, 26 (1). pp. 128-144. \\ ISSN 1350-4630
}

It is advisable to refer to the publisher's version if you intend to cite from the work. http://dx.doi.org/10.1080/13504630.2019.1684887

For more information about UCLan's research in this area go to http://www.uclan.ac.uk/researchgroups/ and search for < name of research Group>.

For information about Research generally at UCLan please go to http://www.uclan.ac.uk/research/

All outputs in CLoK are protected by Intellectual Property Rights law, including Copyright law. Copyright, IPR and Moral Rights for the works on this site are retained by the individual authors and/or other copyright owners. Terms and conditions for use of this material are defined in the policies page.

\section{CLoK}

Central Lancashire online Knowledge www.clok.uclan.ac.uk

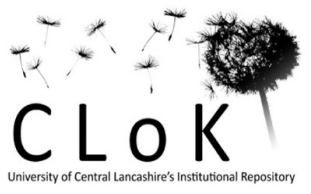




\section{Abstract}

Can we start to say Race again when discussing youth and justice? This demand emerges from the findings of the participatory action research reported in this article. Fifty young people, in custody or in contact with youth offending teams (YOT), discussed the support that would enable them to desist from offending behaviour. Race was a prism through which they saw their experience. Rather than naming racism, family appeared to be a covert, legitimate, way of talking about identity, solidarity and difference. Family ties, overlaid with experiences of race and racism, could be reasons for engaging in behaviour that was seen as criminal. Family, overlaid with ethnicity, could become a source of support to enable young people to cope with the challenges of being involved in and desisting from offending behaviour. At a time where policy and political language has shifted from rac(ism) to a culturalist discourse focused on ethnicity or religion, naming Race and racism remains vital. Only by acknowledging the differentiating power of Racism can the experience of young people in contact with YOT be understood. Only by appreciating the value of shared experience of race (within families and communities) can appropriate pathways towards alternative futures be offered. 
Key words: race, racism, ethnicity, identity, family, YOT

\section{Introduction}

This paper explores the issue that is ever present, but often overlooked by practitioners and policy makers in the UK and elsewhere in Europe when considering young people ${ }^{1}$ and offending. Whilst discussing practice and policy for young people primarily in the UK, comparison will be made to issues of rac(ism) in the US. The issue is silenced by policy discourses within the UK and some other European countries and in young adults' discussions of their life experiences (Gendrot, 2006; Harries, 2014). The issue is race ${ }^{2}$, ethnicity and racism. The paper will draw on research on young people's perspectives on what works in addressing their offending behaviour (Larkins and Wainwright, 2013). A participatory reflective action research methodology, drawing on ideas that dialogue enables actions and change (Friere, 1973), was used to encourage young people to reflect on what was important in their lives, why they felt they became involved in offending behaviour and what they thought was important to help them stop re-offending. Issues of race and ethnicity were recurrently present, but barely named. In defence against this silencing, we draw on

\footnotetext{
${ }^{1}$ The young people referred to in this paper, range from $11-18$ years of age who are protected by Council of Europe (COE, 2010) guidelines on child friendly justice. In the UK they are deemed to be of the age (of criminal responsibility) with which UK Youth Offending Teams work and can be placed in custody as set out by the 1998 UK Crime and Disorder Act. Although, only one participant was 11 years of age, and most (86\%) were 15 to 18 years of age.

${ }^{2}$ Race is not a satisfactory term as it is a social construction based on negative ethnic characteristics. However, it is used in this article as a means of articulating differentiation as a tool for analysis of this difference.
} 
what was said and what was not said by the young people to suggest ways in which naming can support young people in their journeys out of offending.

\section{Race, Ethnicity, Naming and Shaming}

Since the election of Obama it had been argued that US and UK society is viewed through the prism of a 'post-race' era, where the experiences of racism for Black, Asian and Minority Ethnic (BAME) communities has diminished, and in the UK in particular, there has been a vacuum in analysis and production of policies that address issues race and racism (Harries, 2014; Kapoor, 2013; Lentin, 2014; Winnant 2004, 2006). However, the shooting of Michael Brown in Ferguson, Missouri and the last words of 'I can't breath' by Eric Garner before he died in New York, are just two of many recent incidents involving US police officers, that undermine this utopian 'post-race' vision (Guardian, 2014; Mullen, Blake, Crook \& Martin 2014) . Trump's surprise presidential win and support from the white nationalist right in the US has further challenged these assumptions (Lawrence 2017). Yet, many policy makers in the UK, have for a long time argued that the 'problem' of race no longer exists, rather the discourse is that of immigration, cultural difference and integration, and the threat of Islamic terror (Afshar, 2013; Cantle, 2001). These differences are posited in a way that provide a world view of 'Us and Them', which is not defined by any understanding of race or ethnicity, but an essentialist view of the 'Other' that wants to threaten our way of life, by attempting to illegally cross our borders or change the nation's religion by stealth, or force (Afshar, 2013; Kundnani, 2012a). Multiculturalism is blamed for the alleged cultural and religious undermining of the cohesion of communities, and portrayed as the antithesis to integration; whilst diversity and equality policies are promoted as the panacea to these 'challenges' (Cantle 2001, 2005; Kundnani, 2012b; Lentin, 2014. As Harries describes: 
'Race has been replaced by terms of ambiguity that permit confusion and obscure the relations of power. Most obviously this has been documented through the move towards ethnicist and culturalist discourses, which have been interrogated in particular through representations of certain ethnic 'groups'. (Harries 2014, p.4)

This change of language from rac(ism) to a culturalist discourse enables a focus on Islam and its perceived threat locally and globally (Afshar, 2013; Lentin, 2014; Poole 2018). The focus on Islamic terror has been exacerbated with daily media reports of, and politicians responses to, UK born 'jihadists' travelling to Syria and Iraq to fight for the creation of an Islamic state. However, neither local Islamic threats, nor UK jihadists are discussed in terms of the significance of race or racism, rather of importing or exporting Islamic terror (Kundnani, 2012a; Lentin, 2014). Yet, as Lentin notes, racism is central to these discourses:

'the furore over multiculturalism as leading to segregated societies, promoting the growth of Islamic extremism, or enabling the success of the extreme right is not separate from the story of racism; rather, it is its contemporary manifestation.' (Lentin 2014, p.6)

\section{The new Youth Offending Team ${ }^{3}$ (YOT) race: Diversity}

The apparent inability to name racism in UK government and media discourse has changed of recent with the government's own sponsored research on the discrimination BAME people experience in UK society (MacGregor-Smith, 2017), and the publications of the Lammy (2017) and Young reports (Mullen et al 2014) into the experiences of Black, Minority and

\footnotetext{
${ }^{3}$ Youth Offending Teams (YOTs) are the statutory agency in the UK that work with children and young people to prevent them from offending or desist from this behaviour.
} 
Ethnic (BAME) and / or Muslim young men in the criminal justice system. However, recognition of racism has not percolated through to Youth Offending Team (YOT) practitioners and managers where any understanding of the impact of racism is clouded in the language of diversity and policies of Equality (Kapoor, 2013; Kundnani, 2007). The denial of the impact of rac(ism) on BAME and white young people's lives in their daily experiences and within the youth justice system poses serious difficulties regarding the effectiveness of YOT interventions (Goldson \& Chigwada-Bailey, 1999; Hill, 2007; Williams \& Clarke, 2016). It shamefully contributes to a narrative that many young people accept; one of ambiguous denial, it is out there, but it is not openly acknowledged. As Harries points out from research with young people in Manchester,

'respondents who are not read as white-British become caught up in a series of contradictory processes as they talk about multiple levels of experience. These respondents are faced with a particular challenge. They all experience racism and recognise it as such, but in light of 'deracialised' narratives of the city there is a difficulty in naming it. ...In interviews with black and Asian respondents this denial is often in response to the potential to be read as 'victim', but also forms part of the grander narrative about tolerance within the UK and Manchester context in which they are a part.' (Harries, 2014, p. 6)

Thus, the 'micro-aggressions' of racism that young people often feel, experience and confront in their lives are neither represented nor acknowledged in the everyday talk of young people or the language of welfare policy makers and practitioners (Hill, 2007; Rolon- Dow, 2011, p. 164). Instead, the discourse is of culture, Islam, and a patriarchal, social and violent menace from predominantly Pakistani and Bangladeshi men (Chantler, Gangoli \& Hester, 2009; Franceschelli \& O’Brien, 2014; Toor, 2009). 


\section{Police and thieves in the street...}

Police perception of BAME young people in the UK as the 'usual suspects' when offences are committed, has changed little over this same period (Lammy, 2016; Williams \& Clarke, 2016; Wilson, 2006). The Machpherson report (1999) may have dampened stop and search activity, but stereotypes regarding African/Caribbean youth as violent criminals, and south Asian young people as terror suspects are as vivid as ever (Kundnani, 2012a; Williams \& Clark, 2016). Thus, initial contact with the criminal justice system, is based on negative stereotypes the police hold on the basis of perceptions of race, as much as evidence of offending behaviour (Apena, 2007; Goldson \& Chigwada-Bailey 2009; Home Office 2016; Sharpe \& Atherton 2007). These stereotypes persist within the youth justice court system and impact on the sentences BAME children and young people receive in the UK (Lammy, 2016; Mullen et al, 2014; Taylor, 2016)

The socio-economic conditions experienced by many BAME, particularly African/Caribbean young people, mean many find themselves brought up in environments where it is more difficult for them to resist being involved in offending behaviour, or if they are involved in it, to desist from these activities (Allen \& Williams, 2015; Bramley et al, 2015; Nichols, 2017; Wilson, 2006; YJB, 2010). Pathologising African/Caribbean young people informs the negative stereotypes of the community in the UK, US and elsewhere; including a disproportionate tendency to ascribe categories of poor mental health, sexual promiscuity, violence, limited academic achievement, single parent families, and a future only in sport and music (Apena, 2007; Equality \& Human Rights Commission, 2016). These pathologising stereotypes inform the young person's experience of offending behaviour in the community, and decision making process through the youth justice system, even though 
locating their experiences of racism is understood as taboo (Apena, 2007; Goldson \& Chigwada-Bailey 1999; Harries, 2014).

A young person of BAME heritage's experience of racism, poverty and marginalistion may also inform their judgements in whether they resist becoming involved in offending and desist from continuing this behaviour (Mullen et al, 2014). The environments may differ for African/Caribbean, Pakistani and Bangladeshi young people, however how their ethnic heritage is perceived and interpreted by other young people and criminal justice authorities, has a direct and relatively consistent effect on their experience of offending and the criminal justice system (Calverley, 2013; Nichols, 2017; Rolon-Dow, 2011).

\section{YOT Workers: Saying it as you see it ...}

Racial identity is critical in engaging with BAME young people, of African/Caribbean and South Asian heritage as this defines their experience within the criminal justice system and the wider community in a negative sense, along with paradoxically, engendering a positive identity regarding who they are in UK and US society (Apena, 2007). Work can be undertaken that engages African/Caribbean, South Asian and dual heritage young people that experience negative responses to themselves in society and in the criminal justice system. In the late 1980s in the UK, some youth justice workers addressed issues of race and racism that impacted their lives and both the positive and less constructive elements of Black and south Asian culture, enabling YOT interventions from both white and BAME practitioners to be more meaningful and effective for Black, south Asian and white young people (Apena 2007). Yet, the words race and racism are not present in Her Majesty's Inspectorate of Probation 2016 review of UK desistance interventions. Further, in the UK Youth Justice Board library of effective practice, whilst 50 documents do note that either there is monitoring of race 
within youth justice, there are structural inequalities related to race and some young people have racist attitudes, only one resource mentions how addressing the experience of racism can reduce offending. Even our own publication on that site (Larkins and Wainwright, 2013) refers to naming ethnicity and identity, but not how to unsilence racism on the path towards desistence. The conversations with the young people reported in this paper therefore provide much needed guidance on how addressing race now, in the $21^{\text {st }}$ Century, can enhance work with young people who have been involved in offending behaviour.

\section{Methods}

Freire's (1973) approach of reflection, dialogue and action was adopted based on previous research (Rogowski, 1995; Torre \& Fine, 2006; Larkins, 2016) and used to engage a core group of four young people in custody. This core group met for five research sessions in which they reflected on their own experiences and developed interview schedules and activities (which were used by the researchers with a further 46 young people who were attending a YOT, some of whom also had experience of being in custody). Custodial restrictions meant the core group were not permitted to meet with other young people directly however, they developed an initial analysis of the emerging findings. The 46 young people were sampled from anonymised YOT databases to reflect the cohort distribution in the previous 6 months regarding location, offending history, sentence, age and gender plus purposive sampling to ensure inclusion of young people with a range of experiences, for example, homelessness, being in care, substance misuse. After they left custody the young people in the core group chose to no longer be involved in the action research, but other young people continued to inform the research direction and outputs. 


\section{Research Participants}

Participants were recruited from one local authority in Northern England, via open invitation to all young people in one custodial setting where we had $\mathrm{NOMS}^{4}$ ethical permission for access, and via YOTs. To protect against participants being pressured into interviews, researchers reviewed consent at the start of interviews and gave research participants a gift voucher $(£ 10)$ whether or not they participated in the research. Interviewees were sampled from anonymised YOT databases, to reflect age, gender, ethnicity, sentencing and offending history across the population. To protect anonymity, young people quoted in this paper are referred to by pseudonyms and without further identifying details. In total, the research involved 50 young people of whom nine (18\%) were female. Of the 50 young people, four were of Pakistani heritage, or British Asian, two were of dual heritage (African/Caribbean white) and one self identified as white Irish (representing 12\% of the total cohort interviewed). Whilst it is important to acknowledge the self-reported ethnic identities of these (and all) young people, it is equally critical to understand that ethnicity and self-identity are sometimes crude markers for difference, that do not provide a complete picture of an individual's heritage and their understanding of the same (Harman \& Barn, 2005; Wainwright and Ridley, 2012). For instance, it is quite possible that one or more of these young people that self-reported as white may have a grandparent who is (or was) of dual heritage. Thus, when it comes to ethnicity and identity, what one sees, and what one thinks, is not necessarily what one gets (Alibhai-Brown, 2001; Bell, 1996). To emphasise, an individual or young person may outwardly present as white British, but actually could selfidentify as being of dual heritage. Conversely, a young person maybe of dual heritage, but

\footnotetext{
${ }^{4}$ National Offender Management Services
} 
deliberately promote a self-identity of being white British This is important because, when it comes to reflecting on the young people's responses, at times there was an aspect of their identity that was unspoken, that appeared to be really relevant to their lives, their sense of selves and the way they viewed the world. That which was unspoken was their understanding of their experiences of race, ethnicity and their identity (Harman, 2009).

\section{Data analysis}

The research data was initially loaded into NViVo data analysis software and analysed using themes identified by the core group. As the silenced issue of ethnicity and race emerged from this process (Maiter \& Joseph, 2017), the researchers then undertook secondary grounded analysis (Strauss \& Corbin, 2015) to identify transcripts in which race or ethnicity appeared to be present or silenced and then explored these using the question: "What issues of race or ethnicity are present/silenced here?'.

This paper draws on the data from young people who self-identified as being south Asian or dual heritage ${ }^{5}$, but just as importantly, it discusses occasional responses from those that selfidentified as white where race emerged as present or silenced. Sometimes the discussion will not mention, race, ethnicity or difference, but it will be there, in the room, like an unnamed elephant or difficult Uncle that keeps trying to ask the awkward questions, but cannot quite find the language. To illustrate this unspoken tension, this article presents what was said and our interpretation of the silences (Spyrou, 2016).

\footnotetext{
${ }^{5}$ Dual heritage is one of many terms used to describe people who have parentage of more than one ethnicity. Just as mixed race, or mixed ethnicity is not really satisfactory, neither is dual heritage. However, this term focuses on the positive characteristics and differences of ethnicities without ossifying and reifying difference through the term race.
} 


\section{Findings: It's a family affair...}

For those respondents who identified as being of BAME heritage, issues of race, ethnicity and racism were never explicitly named as reasons for being involved in offending behaviour, or as means for reducing their offending. However, family appeared to be a covert, and legitimate, way of talking about identity that made implicit reference to ethnicity. In the first subsection below we provide one discussion which revealed the complex but vital significance of race in young people's lives. In the second subsection we show how family ties, overlaid with experiences of race and racism, were reasons for engaging in behaviour that was seen as criminal. We then turn to how family overlaid with ethnicity could and did become a source of support to enable young people to cope with the challenges of being involved in and desisting from offending behaviour.

\section{What the eyes don't see...}

As already shown, when identifying causes of, and strategies for, reducing offending behaviour, the young people we interviewed never explicitly mentioned race, ethnicity or identity. Yet in other aspects of the research, identity, race or ethnicity and culture did clearly matter to young people we interviewed because it defined who they are, how they see themselves and how others (for good, or not so good), perceive them.

In our discussion with the core focus group of four young people in custody race and ethnicity from time to time came into the conversation ${ }^{6}$. Sometimes discussion arose through making reference to some of the tensions based on race and ethnic divisions between

\footnotetext{
${ }^{6}$ These discussions were not prompted by any questions by the researchers, but it is possible that our physical 'race' presence was a prompt. One of us self identifies as a white British woman, the other as a man of dual, African/Caribbean - white, heritage.
} 
communities. Here, the tensions were apparent through racist views and behaviours within the custodial setting, also from within the white community in any particular town,

Yeah, there seems to be loads of them, there's this, it's like where I live there's a big Asian community and [SMALL TOWN] is big in the Asian community, people tend to be racist.

This comment was made with reference to the amount of African/Caribbean and Asian young people located in a different wing in the custodial setting. However, the young person articulated a wider appreciation of the divisions based on racism in his home town. This conversation was between ostensibly four young white men, who throughout acknowledged that race and ethnicity was a key signifier of difference, and often, conflict. However, at no stage in the discussion did the young people express any views that could be deemed as racist or discriminatory, but ethnicity was clearly identified as a point of difference and conflict for them and their peers, both inside and outside of custody. Yet, it was a discussion between four white young men that the next comment even caught us as researchers, who saw themselves as seasoned observers (experienced) around these issues, by surprise,

I don't see why people should be racist, I've got, I've got my, my sister and brother are half Asian, you know what I mean, come from an Asian family so. If I were to be racist, I'd be racist towards my family, you know what I mean. Don't see point. What the hell's that? 
This young man identifies that some of his family members, are south Asian, of dual heritage, and that although he can identify and feel at ease in a culture that is predominantly white, working class and northern, there is, in fact, much more nuance to his experience than a one view of dimensional ethnicity and culture. Having a family that comprises of at least two ethnicities is very much part of his biography, his story and his sense of belonging and being, but up until that moment, because he is white, and is read as such, there is no sign of an understanding or appreciation of how it may feel to experience racism and discrimination based on ethnicity. It could be suggested, that he has a whole life at home located in an appreciation of ethnic and cultural diversity, or at least dual ethnicities, and another separate life outside the home that is predominantly concerned with white male working class culture. Yet, by this very comment it is evident that he has given it some thought and come to a moral conclusion concerning the pain and hurt that racism can cause people.

The other three young men absorb without direct comment this announcement about his family, his identity and his identification with family members of south Asian heritage. But, the conversation continues as another young man explains how divisions around race and ethnicity are played out in custody,

And same thing there, you know what I mean, if it's a black person or white person who's fighting, you're going to obviously back ...the white person and they'll do same with the black person, it's same things in a way, so that's like, if there is trouble in here and out there, if you get what I'm saying. That's what most people get excluded for, for doing silly little things like that and we're all human at end of day, and still doing it, never change 
So it matters. Race, racism and ethnicity matter in these young men's social relations in their own communities, at home, or in and through their negotiation and conflict in custody. Through the negotiation of identities and belonging people take sides based on their purported identities. To be human is to belong and through necessity of survival in custody and their own communities these young men understand that they need to takes sides. However, the nuanced understanding of common humanity, albeit through difference, and often conflict is understood by them.

One says,

\section{'Both human'}

Then one of the other young men,

'Only skin colour isn't it, you know what I mean?'

This last comment is made by the young man who had just declared that he had members of his family that were south Asian and of dual heritage. But both participants demonstrate a sensitivity to difference in race and ethnicity, a commonality of human experience and an ability to discuss these issues sensitively.

\section{What the words don't say. . . Getting into trouble}

Two young Asian women who were part of the same family, Aisha and Shazia, discussed how they become involved in offending behaviour and consequently why they started attending a YOT. As south Asian young women of Pakistani/ Muslim heritage they had moved from one 
area of England to another and were in the process of settling in, establishing themselves and dealing with bullying. Aisha explained:

'They were teasing a friend of ours, a close family friend, and she was scared so she came and told me... The girl [who had been teasing my friend] ...knew who I was, because obviously you're new to the area, people know you. And she came up and she was saying "I like your brother, I want to marry him", and stuff like that, she's like swearing out

Shazia explains how she felt obliged to fight back to protect this close family friend and her family member Aisha:

She started on my family then, Aisha. And Aisha couldn't move away. So that girl then grabbed Aisha. So obviously I tried to drag her off my family and she went and grabbed my hair, so I grabbed hers. So, you know, I had a bandage, stitches on mine so I couldn't use one hand, I only could use the other one. So somehow we got done for it! We had to pay a fine.

The discussion then centred on the young woman trying to protect her family and their patch as they were new to the area.

Throughout this conversation there is no reference to their ethnic and cultural difference between themselves and the girl who insulted them, or how they experienced where they lived whilst committing the offence, and attending the Youth offending team. This could be because, quite rightly, they viewed their own ethnicity, their own identity as normal. Yet in this dispute, and their subsequent behaviours in the fight, their difference, as young south Asian, Muslim women, appears to be context to their reason for their actions. The new social networks they 
were establishing were with family friends. The insult against the brother, which sparked the fight, related to issues of marriage and swearing. We read the silences within this discourse to suggest that the family friend was of a similar south Asian background. And, based on evidence from other research with south Asian young women experiencing bullying at school (Mirza and Meetoo 2018), the swearing and insults about the brother are likely to be taunts within the context of their ethnic/cultural differences related to identity and possibly marriage practices. To survive in this hostile world, these young women, Asian women, Muslim women, relied on their family, and defended their identity/culture and each other as family members with shared racialised identities.

\section{What the words don't say. . . Getting out of trouble}

The importance of family in dealing with (in) difference and disengagement with those around them including their Youth Offending Team was evidenced by two young men. The first, a young man of dual heritage, Colin, demonstrated indifference in his halting inarticulate responses. The discussion centred around whether he felt he gained anything from attending the YOT team and Colin's responses reflect a total disengagement from the whole process:

Well I do sometimes do some work or sometimes, ... do you know what I mean like, ... I don't know, don't know what I expect of her [YOT worker] like, don't expect much of her, to be honest.

This is one of several responses from Colin that indicates he sees no value in attending the YOT. His worker has not engaged him and he does not see her as offering him anything much. Either way, he does not want to be there. When asked whether the YOT, his worker or the entire experience has been beneficial to him at all he says, 
It is, is, to some people maybe but to me like I don't know, it's different really, do you know what I mean? It's just, I don't know, I don't know, it's, know what I mean?

With prompting he continues:

I wouldn't really be bothered to be honest if there's anything, you know, not, I just want to get it done, it's just coming here that just, it's annoying, do you know what I mean, having to take it out your day to come here in'it, know what I mean?

Colin's reply is brutal and honest and could be argued to reflect how many young people feel when mandatory orders oblige them to attend YOTs. However, there was something in the way that he said "different" together with his physical appearance that led the interviewer to think the difference he was in part referring to, may relate to race. The discussion echoed the interviewer's own experience and that of working with African/Caribbean young men. This interpretation was in part corroborated when the interviewer named his understanding of young people's experience of racism and Colin responded by talking more openly. It could be because there is nothing in Colin's experience, his sense of identity, that chimes with being at the YOT every week. This lack of relevance may be exacerbated because his YOT worker is white and female, and the area where he attended a YOT is predominately white. This difference may have been informed by gender, and/ or race, and the fluid experiences of intersectionality, identity and (not) belonging (Mullen et al, 2014; White, 2008) There is a further contrast between his discussion of YOT and when Colin started to talk more expansively about his father, who is also of dual heritage. Since school, Colin has worked for him:

Got his own painting and decorating business innit, so I'm doing it with him, I've done loads of jobs like. I wasn't in school, I got kicked out of school and I was like, in Year 
Nine or something. Yeah, I've been out of school since then, eight, Year Eight or Nine or summat, know what I mean, so?

Colin's relationship with his father and how he gains personal satisfaction and fulfilment in working with him appear to be his main priority. He is engaged and committed to this.

So how are we to interpret how completely dismissive Colin is of the whole process of attending a YOT which has failed to engage with him on any level? Colin may be disengaged with the YOT because of his personality and his sense of self. Where he feels he is in his journey in life may be a key factor. Maybe because he does not have the words to express how he feels, or possibly because he does. However, learning from research with other professionals (Apena, 2007; Harman, 2009) and our reading of the word "different" and the silences, suggests the dismissiveness of YOT also relates, in part, alongside issues of gender, to the absence of naming race, racism and engaging with these issues.

Although it may seem like a stretch, on the basis of this one example, to link lack of engagement with YOT with lack of engagement with issues of ethnicity, a third example, is where a YOT worker appears to engage with issues of family, identity and dual heritage (although this is never clearly articulated). A young man, Jamie, described his increasing engagement with YOT. Jamie's parents lived apart and he had grown up living with both of them at different times. He described being kicked out by every member of his family after having 'behaved like a scumbag' by stealing to feed his drug habit. He described his first YOT worker as unpredictable:

He was just being, everything, just little things, just being awkward and that, he breached me, he'd go, try and go mad if I was ten minute late or summat like that, so, being awkward ... Like sometimes I'd speak to him and he'd be like, be alright. And other times he'd just be a bit of a knobhead. 
When Jamie's YOT worker was changed Jamie became more engaged. Jamie described his second worker as someone he could talk to about anything. Although during his interview, Jamie made no mention of discussing his dual heritage with this second worker, it is apparent that the worker had encouraged him to re-establish a connection with his father (of African/Caribbean heritage).

Yeah, well YOT helped as well, because they were saying about, it's important to have a relationship with your Dad. My dad plays football and so he's a good footballer.

Earlier in the research interview Jamie had also identified support he had received from the second YOT worker and an assistant to get back into playing football. Jamie training as a coach had been a crucial part of him getting out of offending behaviour. At the end of this interview (65 minutes) and glowing with pride, Jamie described how he had managed to turn his life around and stop offending by building his relationship with football and his father.

I played with him [my Dad] not long ago, and that's first ever time. He's forty-one, and he was saying to me he can hang his boots up now because he's played with me and my brother, the same team, so, it's alright.

Whilst with both of these examples it would be possible to argue that the crucial factor may be relationships with fathers, or meaningful activity, rather than ethnicity, this combination of factors (meaningful activity, fathers and reduced offending) was much more evident in interviews with BAME young people than with other young people in the sample. Spontaneous conversations about the role of fathers happened in three of the nine interviews with BAME young people, compared with only one of the 41 White British young people. This could also be because BAME men (as fathers) are statistically more likely than white 
men to have been incarcerated at some point in their lives, and therefore, the relationship with their fathers even more important if they are not in prison (Hopkins, 2015; Lammy, 2016).

Feeling useful or engaged in a meaningful activity also appears to be important, as Hamid, a British Asian young man (of Pakistani heritage) described. First, he is talking about his relationship with his YOT worker:

You don't want to feel useless and stuff, you want to be listened to.

\section{INT And do you think, does that happen?}

$$
\text { [.....long pause.... No answer] }
$$

Unlike Jamie and Colin, Hamid did not seem to benefit from relationships with family members or YOT workers who could enable him to access to the kind of meaningful activities he wanted to engage with. However, family was still an important source of support for him,

telling your problems to a stranger? You'd rather tell, rather go to one of your family members or someone you know close, like a close friend.

Hamid does however talk about the kind of community work that he would want to engage in through YOT:

the community work you have to do is like leafleting and like burning things, what's that got to do with anything? Like you may, if you have to do community work at least be summat like having to go help someone out or something, like that, you know what I mean? Summat useful. ... so at least like someone could say "I've been helped out, it's like someone helped me out." 
Hamid, in these extracts, talked about YOT workers as strangers, but he was keen to provide support to people he did not know; he did not specify which community members he thought he should be helping. However, extrapolating from the cases that show it may be productive for YOT workers to name issues of race and racism when working with young people, it may also be useful to consider ethnic/cultural constructions of community and community work. This suggestion is reinforced by research which indicates cultural differences in how forms of community volunteering are valued (Peucker, 2018). Ethnically appropriate community work might enable young people who do not have family-based opportunities (working or doing sport with fathers), to take part instead in meaningful activities in communities which could provide the sorts of rewarding interpersonal interactions Hamid seeks. Naming issues of race and racism here would mean exploring whether activities in communities enable young people to have a sense of shared identity or at least where their ethnic identity is not the source of further unspoken racism.

\section{Discussion}

The purpose of this paper was to explore the experiences of fifty young people in the UK criminal justice system through a participatory action research project. In particular, how their experiences of race, racism and ethnicity could be better understood and empowered by YOT workers to enable them to desist from future offending.

The silences from the participants who were of a different ethnicity, Asian, dual heritage (African/Caribbean- white) and the discussions from the white young men in custody indicate that race and ethnicity is very much the elephant in the room. It is still very often thought about and acted upon, yet in many cases not identified, discussed or named by YOT workers. Aisha's and Shazia's responses and the conflict in their local community arose not only 
because of their ethnicity and culture. But, their response towards the other girl was located within their cultural understanding of their difference and the differentiation they were experiencing, as south Asian Muslim young women in an unfamiliar new neighbourhood. To protect family and a family friend, was paramount. Providing mechanisms for the reporting and discussing racism at school may help avoid an experience of racism turning into experience of the youth justice system. This could be through a school ambassador or lead for equality working with teachers to provide safe spaces for young people to feel comfortable to discuss such experiences. Enhanced teacher understanding of racism is also needed (Mirza and Meetoo 2018). Attention to providing effective approaches to dealing with bullying in schools is particularly important in this time of Brexit transition within the UK and school league tables, as the British Youth Council and Equality and Human Rights Commission report that racist taunts are on the increase and racist bullying is being 'swept under the carpet' in order to avoid poor Ofsted inspection results (Pells, 2016). Clear school policies to address bullying that is manifested through discrimination and racism should be developed within the context of a Brexit anti-migrant culture, that articulates, and is sensitive to, the intersectional experiences of difference for young Muslim women and other BAME young people (Glynn, 2016). Along with delivery of training on the impact of racism to professionals within the legal, youth justice and education systems.

Colin, albeit very reluctantly, was aware of his evident difference, but this difference appeared not to be named, he just felt different. It is possible that he still would have been reticent to engage in the YOT's activities even if his ethnicity was acknowledged as a positive part of his identity, but his sense of difference seemed to exacerbate his antipathy to all things related to the YOT. When Jamie's worker did appear to engage with difference, related to his dual heritage, his engagement with YOT increased and he moved closer to desistance. However, just as with Colin, in Jamie's description of this process, and in the 
worker framing of the importance of a relationship with his father, race and ethnicity remained un-named. Learning from comments by young adults slightly older than Jamie (see Mina in Harries, 2014), this may be a process of self-silencing, in which a young person who has experienced racism hesitates to describe the importance of shared identity (and the feelings of safety that can be associated with this). In Mina's case, and so possibly in Jamie's case, this was because she feared being thought of a racist against white people. As Harries (2014) reflects, Mina's self-silencing may have been particularly strong as the interviewer was white British. Jamie was also interviewed by the white British researcher in our study, and although we tried, we were unable to set up a further interview with the lead author of this paper, whose race identity, or insider position (Obasi, 2014) may have made selfsilencing less likely to occur.

Where it is not possible to provide young people with options of engaging with YOT staff who share an insider position, white researchers and YOT workers could learn from the four young men who, although they appeared to have no biographical insider experience of difference based on race and ethnicity, were far more forthcoming about the problems and conflict that can manifest in divisions based on this difference. If professionals start unsilencing race and racism in their interactions with all young people by actively naming and providing safe spaces to discuss it, overlapping layers of identity and structural contexts may be better understood and paths towards desistance carved out in these territories (Nichols, 2017). Here there may be lessons to learn from the Anti-Racism Collaborative of the American Public Health Association Learning which suggests inquiry into strategies for naming and dialogue, education, implementing international rights provisions and unpicking historical patterns within institutions and linking to communities, as well as developing the research excellence and policies and values to enable change (Jones 2018). 
A further clearly effective pathway to desistance appears to arise from increasing engagement in meaningful activities with a family member of shared minoritized identity. In the limited examples available to us in this study, the family member was always the father, so shared gender identity may also be significant. As Hamid suggests, and our further research shows (Larkins, 2019), where (male) family members are not able to provide these roles, then elders or broader community members may also have a positive effect where there are opportunities to engage together in meaningful social contributions which result in positive feedback.

These experiences are yet more manifestations of the paradox of race and ethnicity. On the one hand as the boys/young men in custody point out, there are clear markers based on these differences (Gunaratnam, 2003), yet on the other, notions, and our perceptions, of race and ethnicity are in a constant state of flux constantly being (re)-negotiated in a dialogue between individuals and communities (Caballero, Edwards \& Puthussury, 2008). Hence, notions of ethnicity can be seen, in the case of the young man with south Asian siblings, as neither fixed nor singular, but fluid over different spaces and places (Hall, 1991; Wainwright and Ridley, 2012). Further, as with this young man, within the difference of the experience of dual heritage individuals and families, there is an 'ordinariness' in the way they negotiate their lives (Caballero, Edwards, Goodyear \& Okitikpi, 2012). This may manifest itself in a positive way, if it is re-affirmed as such by others around them, or a negative way if the experience in a micro location is one of racism (Harman, 2009). This constant (re)negotiation can be seen in the experience of the young people that participated in this research, be they south Asian young women, engaged in conflict in their new local community, two young men of dual heritage or/ and one south Asian young man not wanting to engage with YOT workers when they were read as strangers and showed no clear indications of what could be expected of their understanding of race, ethnicity or identity; or 
the four white boys/young men who were painfully aware of the markers of race, ethnicity and difference. These markers are manifested in separate and alienated Muslim/ Pakistani communities (for the young women), difference in biography, heritage and physical appearance for the dual heritage young men, and the violence that can erupt from racism (for the four young men in custody).

\section{Conclusion}

These experiences of difference, of race, ethnicity and, in some cases the consequent racism, have implications for interventions with young people in contact with youth justice services in the $21^{\text {st }}$ Century. Although this study was conducted within the UK, these implications are of international relevance given the context of the Council of Europe Guidelines (2010) which expressly ban discrimination on the grounds of race, but which fail to identify strategies for remedying ongoing experiences of racism. If professionals are to engage meaningfully with young people (however they self-identify, whatever their complexion, whether difference is visible to the eye or not), professionals need to find the language, the medium, to enable their interventions to have real meaning. This will involve practitioners being comfortable discussing $\mathrm{rac}(\mathrm{sim})$ with young people and actively encouraging young people to feel able to do so. Placing practitioners of BAME heritage in a team working with young people who engage in offending behaviour is a start. BAME practitioners provide the opportunity to share insider status and work with BAME young people individually, in groups and can enable a culture, where teams of both white and BAME practitioners can discuss issues and develop polices in a safe learning environment. But, this will not address the shifting sands of identity, ethnicity and racism, that these young people have articulated here and about which other young people have raised concern in the context of Brexit (Larkins, 2017). There needs to be a re-engagement with young people, by all professionals, to unsilence and explore their experience, their daily lives, how they are negotiating race and 
ethnicity and how it effects, or not, their chances of (re)-offending. This can be done by placing rac(ism) right at the front and centre of any contract of engagement with BAME young people in contact with services focused on reducing offending. Gaining an understanding of these diverse and fluid experiences should inform the way professionals work with young people in the future. Thus, practitioners need to learn and listen about the experiences of BAME young people, and BAME colleagues in all their heterogeneity through focused training and team discussion. The wider research from which this study on ethnicity is drawn shows that young people want to develop meaningful relationships with their workers to help them navigate their lives to stop re-offending (Larkins and Wainwright, 2013). Identifying, naming and addressing race, racism and ethnicity, that big clumsy elephant in the room, is a key part of this process.

This study provides pointers for future research regarding working with young people of BAME heritage who have been involved in the criminal justice system. In particular, exploring narratives, the stories, of Muslim/ Pakistani and African/Caribbean young people (of both genders) and those of heterogeneous identities of dual ethnicity who have ended up in contact with criminal justice systems across Europe. In particular, research should focus on how their multiple, diverse and intersectional identities inform their experience of offending and how to support strategies to resist. 


\section{References}

Afshar H (2013) 'The politics of fear; What does it mean to those who are otherized and feared?' Ethnic and Racial Studies 36 (1) 9-27

Allen, P., \& Williams, P. (2015). We Tell You Peer Based Community Research Interim Findings for Young Black Men's Perspectives on Mental Health. Retrieved from http://42ndstreet.org.uk/wordpress/wp-content/uploads/2016/06/We-Tell-You-InterimReport-November-2015-Final-Version.pdf

Alibhai-Brown Y. (2001) Mixed Feelings: The Complex Lives of Mixed-Race Britons London, The Women's Press Ltd.

Apena, F. (2007). Being Black and in Trouble: The Role of Self-perception in the Offending Behaviour of Black Youth. Youth Justice , 7 (3 ), 211-228. http://doi.org/10.1177/1473225407082511

Bell, V. (1996) 'Show and Tell; Passing Narrative in Toni Morrison's Jazz.' Social Identities: Journal for the study of Race, Nation and Culture. Vol 2. No 2 pp221-236

Bramley, E. G., Fitzpatrick, S., Edwards, J., Ford, D., Johnsen, S., Sosenko, F., \& Watkins, D. (2015). Hard Edges Mapping severe and multiple disadvantage. Retrieved from www.lankellychase.org.uk

Caballero C., Edwards, R. and Puthussery S. (2008) Parenting 'mixed' children: negotiating difference and belonging in mixed race, ethnicity and faith families. Joseph Rowntree Foundation: York 
Caballero C., Edwards, R. Goodyear, A. and Okitikpi, T. (2012) The Diversity and Complexity of the Everyday Lives of Mixed Racial and Ethnic Families: Implications for Adoption and Fostering Practice and Policy Adoption and Fostering Vol: 36 issue: 3-4, pp 9-24

Calverley, A. (2013). Cultures of Desistance: Rehabiliation, reintegration and ethnic minorities. Oxon: Routledge.

Cantle T. (2001) Community Cohesion: Report of the Independent Review Team - The 'Cantle Report' (Cantle 2001). London: Home Office

Cantle T. (2005) Community Cohesion: A New Framework for Race and Diversity. Basingstoke: Palgrave Macmillan

Chantler K, Gangoli G and Hester M (2009) Forced marriage in the UK: Religious, cultural, economic or state violence? Critical Social Policy 29(4): 587-612.

Council of Europe (2010) Guidelines of the Committee of Ministers of the Council of Europe on child-friendly justice https://rm.coe.int/16804b2cf3 [accessed 18.1.19]

Equality and Human Rights Commission (2016). Healing a divided Britain: the need for a comprehensive race equality strategy Who is it for? What is inside? Retrieved from https://www.equalityhumanrights.com/sites/default/files/healing_a_divided_britain__the_need_for_a_comprehensive_race_equality_strategy.pdf

Franceschelli M. and O'Brien M. (2014) ' 'Islamic Capital' and Family Life: The Role of Islam in Parenting' Sociology. published online 17 February 2014 1-17 
Freire, P. (1973) Pedagogy of the Oppressed. Seabury Press, New York.

Gendrot, S. (2006). France: The politicization of youth justice. J. Muncie \& B. Goldson (eds.), Comparative Youth Justice. Critical Issues, 48-64.

Glynn, M. (2016). Towards an intersectional model of desistance for black offenders. Safer Communities, 15(1), 24-32. http://doi.org/10.1108/SC-05-2015-0016

Goldson B. and Chigwada-Bailey R. (1999) '(What) Justice for Black Children and Young People.' in Goldson B. (ed) Youth Justice; Contemporary Policy and Practice pp51 -74 Aldershot: Ashgate.

Gunaratnam Y. (2003) Researching 'Race' and Ethnicity. Sage: London

Hall S, (1991) 'Old and new identities, old and new ethnicities', in King AD (ed), Culture, Globalization and the World System, Basingstoke: Macmillan

Harman V (2009) ' Social Work Practice and Lone White Mothers of Mixed-Parentage Children' British Journal of Social Work. Vol 40, Issue 2, 1 pp 391-406,

Harman V. and Barn, R. (2005) 'Exploring the discourse concerning white mothers of mixed-parentage children', in T. Okitikpi (ed.), Working with Children of Mixed parentage, Dorset, Russell House Publishing

Harries B. (2014) 'We Need to Talk about Race.' Sociology Vol 48 (6), 1107-1122 Hill J. (2007) 'Daring to Dream: Towards an Understanding of Young Black People's Reflections Post-custody.' Youth Justice. 7 (1), 37-51 
HM Inspectorate of Probation (2016) Desistance and young people

https://www.justiceinspectorates.gov.uk/hmiprobation/wp-

content/uploads/sites/5/2016/05/Desistance_and_young_people.pdf

Home Office (2016) Police powers and procedures, England and Wales, year ending 31 March 2016. Retrieved from:

https://www.gov.uk/government/uploads/system/uploads/attachment_data/file/562977/po lice-powers-procedures-hosb1516.pdf

Hopkins, K. (2015). Associations between police-recorded ethnic background and being sentenced to prison in England and Wales. Retrieved from

https://www.gov.uk/government/uploads/system/uploads/attachment_data/file/479874/a nalysis-of-ethnicity-and-custodial-sentences.pdf

Jones, C. P. (2018). Toward the Science and Practice of Anti-Racism: Launching a National Campaign Against Racism. Ethnicity \& disease, 28 (Supp 1), 231-234.

Kapoor N. (2013) 'The advancement of racial neoliberalism in Britain.' Ethnic and Racial Studies. 36 (6), 1028-1046

Kundnani A. (2007) The End of Tolerance: Racism in Twenty-First Century Britain. London: Pluto Press.

Kundnani A. (2012a) 'Radicalisation: the journey of a concept.' Race and Class. 54 (2), $3-25$

Kundnani A. (2012b) 'Multiculturalism and its discontents: left, right and liberal.' European Journal of Cultural Studies. 15 (2), 155-16. 
Lammy D. (2016) An independent review into the treatment of, and outcomes for, Black, Asian and Minority Ethnic individuals in the Criminal Justice System. https://www.gov.uk/government/uploads/system/.../lammy-review-final-report.pdf Lawrence B. (2017) Racism in Trump's America: reflections on culture, sociology, and the 2016 US presidential election._British Journal of Sociology Supplement S1, Vol. 68, pp85-S104.

Larkins, C. (2016) Making the Critical Links: Strategies for Connecting Marginalised Children's Action Research with European Citizenship. Social Work Review, anul XV, 2/2016, www.swreview.ro

Larkins C. (2017) We're still waiting for answers! Responding to children's questions on Brexit. In Children and the Risks of Brexit, 20 November 2017, European Parliament, Larkins C. (2019) Excursions as Corporate Agents: A critical realist account of children's agency. Childhood 26(4) 414-429 https://doi.org/10.1177/0907568219847266

Larkins C. and Wainwright J. (2013) 'Just putting me on the right track': Young people's perspectives on what helps them stop offending. Project Report. Preston, Lancashire: University of Central Lancashire.

Lentin. A. (2014) 'Post-race, post politics: the paradoxical rise of culture after multiculturalism.' Ethnic and Racial Studies. 37 (8), 1268-1285

MacGregor-Smith R. (2017) Race in the Workplace: The time for talking is over now is the time to act. https://www.gov.uk/government

MacPherson W. (1999) The Stephen Lawrence Inquiry. HM Gov.uk. Stationary office 
Maiter S. and Joseph A. (2017) 'Research Racism: The Colour of Face Value, Challenges and Opportunities.' The British Journal of Social Work. Vol 47, Issue 3 pp755-772

Mirza, H.H. \& Meetoo, V. (2018) Empowering Muslim girls? Post-feminism, multiculturalism and the production of the 'model' Muslim female student in British schools, British Journal of Sociology of Education, 39:2, 227-241

Mullen, J., Blake, M., Crook, J., \& Martin, C. (2014). The Young Review: Improving outcomes for young black and/or Muslim men in the Criminal Justice System Final Report. Retrieved from http://www.youngreview.org.uk/sites/default/files/clinks_youngreview_report_dec2014.pdf

Nichols N (2017) 'Technologies of evidence: An institutional ethnography from the standpoints of youths at risk. Critical Social Policy. Vol 37: Issue 4 pp604-624

Obasi C (2014) ' Negotiating the insider/outsider continua: a Black female hearing perspective on research with Deaf women and Black women' Qualitative Research Vol: 14 issue: 1 , pp: $61-78$

Pells, R. (2016) Racist incidents 'being covered up in schools' to protect Ofsted ratings, report warns The Independent Saturday 19 November 2016 12:16 https://www.independent.co.uk/news/education/education-news/racist-religious- 
discrimination-incidents-covered-up-schools-protect-ofsted-ratings-youth-selecta7426556.html

Mario Peucker (2018): Muslim community volunteering: the civic-religious 'culture of benevolence' and its sociopolitical implications, Journal of Ethnic and Migration Studies, DOI: 10.1080/1369183X.2018.1543020

Poole E (2018) 'Constructing "British Values" within a Radicalisation Narrative: The reporting of the Trojan horse affair' Journalism studies Vol 19 Issue 3 pp 376-391

Rogowski, S. (1995) 'Youth crime and community based initiatives: A critical look at their development and some thoughts on a radical practice', Practice: Social Work in Action, 7:4, 43-52

Rolon-Dow R. (2011) 'Race(ing) stories: digital storytelling as a tool for critical race scholarship.' Race, Ethnicity and Education. 14 (2) 159-173

the Guardian (2014) 'I can't breathe': Eric Garner put in chokehold by NYPD officer' Thursday $4^{\text {th }}$ December

Sharpe, D., \& Atherton, S. (2007). To Serve and Protect?: The Experiences of Policing in the Community of Young People from Black and Other Ethnic Minority Groups. British Journal of Criminology, 47(5), 746-763. http://doi.org/10.1093/bjc/azm024

Spyrou, S. (2016). Researching children's silences: Exploring the fullness of voice in childhood research. Childhood, 23(1), 7-21.

Strauss A and Corbin J (2015) Basics of Qualitative Research: Techniques and procedures for developing grounded theory. Sage: London 
Taylor C. (2016) Review of the Youth Justice System in England and Wales. https://www.gov.uk/government/...data/.../youth-justice-review-final-report-print.pdf

Toor S. (2009) 'British Asian Girls: Crime and Youth Justice.' Youth Justice Vol 9 (3) $239-253$

Torre M. and Fine M. (2006) 'Intimate details: Participatory action research in prison.' Action Research. Volume: 4 issue: 3, page(s): 253-269

Wainwright J. and Ridley J. (2012) 'Matching, ethnicity and identity: Reflections on the practice and realities of ethnic matching in adoption'. Adoption and Fostering Vol 36 (3). pp. 50-61

Walters J. (2014) 'Thousands march in New York over Garner and Brown police deaths' http://www.theguardian.com/world/2014/aug/23/new-york-eric-garner-rallymichael-brown. Accessed $26^{\text {th }}$ June 2015

White, R. (2008). Disputed definitions and fluid identities: The limitations of social profiling in relation to ethnic youth gangs. Youth Justice, 8(2), 149-161. http://doi.org/10.1177/1473225408091375

Williams, P., \& Clarke, B. (2016). Dangerous associations : Joint enterprise, gangs and racism An analysis of the processes of criminalisation, (January). Manchester Metropolitan University

Wilson D. (2006) 'Some Reflections on Researching with Young Black People and the Youth Justice System.' Youth Justice 6 \{3) 181-193 
Winant H. (2004) The New Politics of Race: Globalism, Difference, Justice.

Minneapolis: University of Minnesota Press.

Winant H. (2006) Race and racism: Towards a global future. Ethnic and Racial Studies.

$29(5), 986-1003$.

YJB. (2010). Exploring the needs of young Black and Minority Ethnic offenders and the provision of targeted interventions Exploring the needs of young Black and Minority Ethnic offenders and the provision of targeted interventions 2. Retrieved from www.yjb.gov.uk 
